\title{
Dural Metastasis with Subdural Hemorrhage from Prostate Cancer
}

\author{
Kantenga Dieu Merci Kabulo ${ }^{1, ~ *}$, Nathaniel Harunangoni Zimani ${ }^{1}$, Aaron Masiiwe Musara ${ }^{1}$, \\ Patrice Ntenga $^{3}$, Khita Phiri ${ }^{2}$, Kazadi Kaluile Ntenga Kalangu ${ }^{1}$, Rudo Makunike Mutasa ${ }^{2}$ \\ ${ }^{1}$ Department of Neurosurgery, University of Zimbabwe, Harare, Zimbabwe \\ ${ }^{2}$ Department of Pathology, University of Zimbabwe, Harare, Zimbabwe \\ ${ }^{3}$ Neurological Clinic of the National Teaching Hospital-FANN, Dakar, Senegal
}

Email address:

dmkabulo@gmail.com (K. D. M. Kabulo)

${ }^{*}$ Corresponding author

\section{To cite this article:}

Kantenga Dieu Merci Kabulo, Nathaniel Harunangoni Zimani, Aaron Masiiwe Musara, Patrice Ntenga, Khita Phiri, Kazadi Kaluile Ntenga Kalangu, Rudo Makunike Mutasa. Dural Metastasis with Subdural Hemorrhage from Prostate Cancer. International Journal of Neurologic Physical Therapy. Vol. 3, No. 6, 2017, pp. 49-53. doi: 10.11648/j.ijnpt.20170306.11

Received: August 13, 2017; Accepted: August 28, 2017; Published: December 18, 2017

\begin{abstract}
A subdural hematoma (SDH) is usually traumatic in etiology. Non-traumatic instances of SDH are uncommon, and are rarely due to metastases involving the dura. We report a 68-year-old male patient with a one day history of, not communicating and not mobilizing and a 2 weeks history of generalized body weakness. A computed tomography (CT) scan revealed a left sided hypo-dense subdural collection. A diagnosis of left sided chronic subdural hematoma (SDH) was made. Burr hole drainage of the hematoma was performed. Intra- operatively, liquefied blood was drained and a thick dura with reddish material infiltrating the dura was noted. A specimen of the dura was submitted for histology and revealed metastatic carcinoma, confirmed at immunohistochemistry to be of prostatic origin. Conclusion: Metastatic disease should be considered when there is a chronic subdural hematoma with no history of trauma and an unusual dural appearance on imaging.
\end{abstract}

Keywords: Prostate Cancer, Dural Metastases, Subdural Hematoma

\section{Introduction}

Metastases to the dura mater constitute one of the least frequent and least studied patterns of neoplastic spread to the cranio-spinal axis [1]. Rarer still, is the occurrence of subdural hematomas (SDHs) associated with dural metastasis of a malignant tumor [2]. We report a case of a subdural haematoma presumably caused by metastasis from prostate cancer located on the dura mater.

\section{Case Presentation}

A 68-year-old male patient was referred with a one day history of not communicating, not walking and two week history of generalized body weakness.

He had no history of head trauma. On admission to the hospital, he appeared chronically ill with wasting and pallor.
His vital signs were within normal limits.

His level of consciousness was 7/15 and he had unequal pupil sizes with the right $2 \mathrm{~mm}$ and Left $5 \mathrm{~mm}$ with the right sluggishly reacting to light. Noted also was right sided hemiplegia. He was tachypnoeic and had bilateral chest crepitations.

A computed tomography (CT) scan revealed a hypo-dense subdural collection and chest $x$ ray showed diffuse heterogenous opacification on left hemithorax. Diagnoses of left sided chronic subdural hematoma (SDH) and aspiration pneumonia were made.

The full blood count showed anemia with hemoglobin of $8.6 \mathrm{~g} / \mathrm{dl}(12-16 \mathrm{~g} / \mathrm{dl})$. Urea, creatinin and electrolytes were normal.

Liver Function Tests showed elevated ALP of 1389IU/L (44-147IU/L) and slightly decreased albumin of $27 \mathrm{~g} / \mathrm{L}$ (30$53 \mathrm{~g} / \mathrm{L})$. 


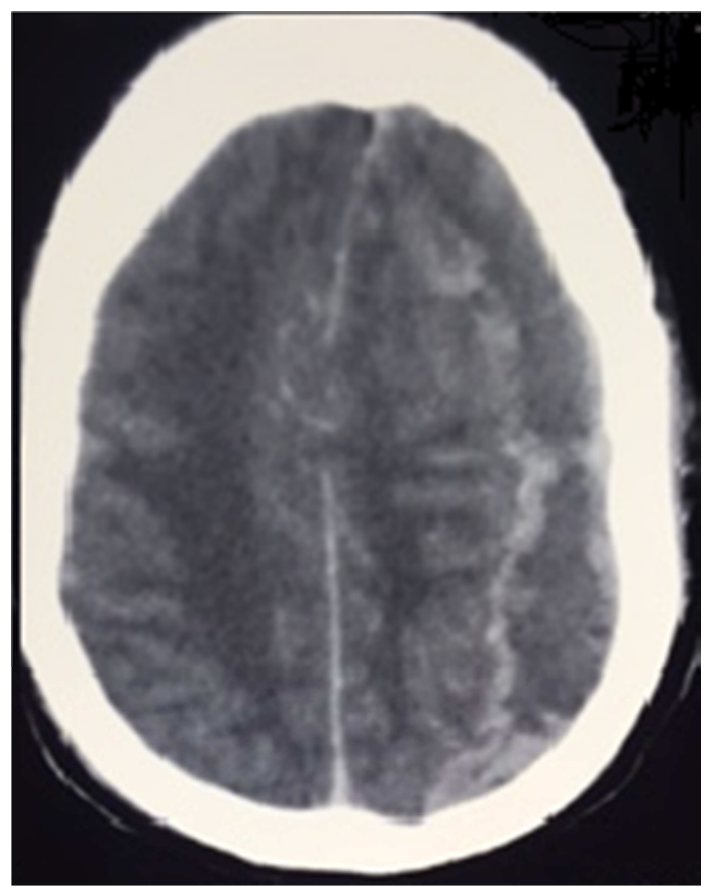

Figure 1. Axial non contrast head Computed Tomographic image shows a crescent-shaped hypodense fluid collection in the left parieto-occipital subdural space, consistent with an chronic subdural hematoma with midline shift to the right side.

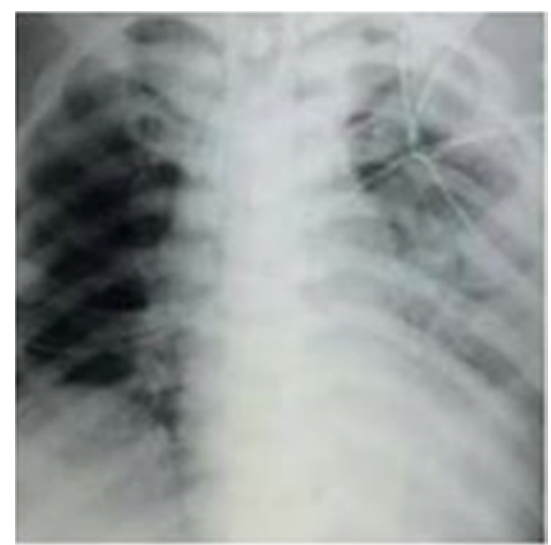

Figure 2. Chest radiograph: diffuse heterogenous opacification on left hemithorax.

The patient was taken to theatre for evacuation of the subdural collection.

Intra-operatively, liquefied blood was drained and the dura was noted to be thickened with reddish material in it. A specimen of the dura was submitted for histopathological examination and revealed metastatic carcinoma. The lesional cells were positive for PSA antibody on immunohistochemistry confirming prostatic origin.

Histology:
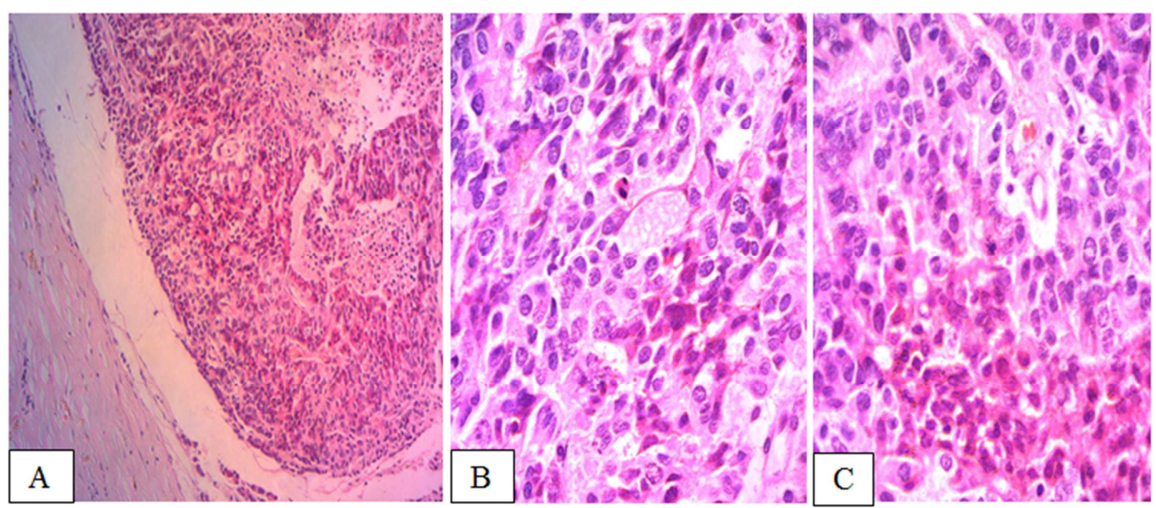

Figure 3. Microscopic findings: sections show fibrous tissue infiltrated by a tumor consisting of vague nets and sheets of polygonal cells with eosinophilic cytoplasm and markedly pleomorphic nuclei with prominent nucleoli. The lesional cells also show a linear pattern of infiltration. The tumor is mitotically active with areas of necrosis seen. A: X10; B:X40 and C: X100.

\section{S100 PROTEIN}
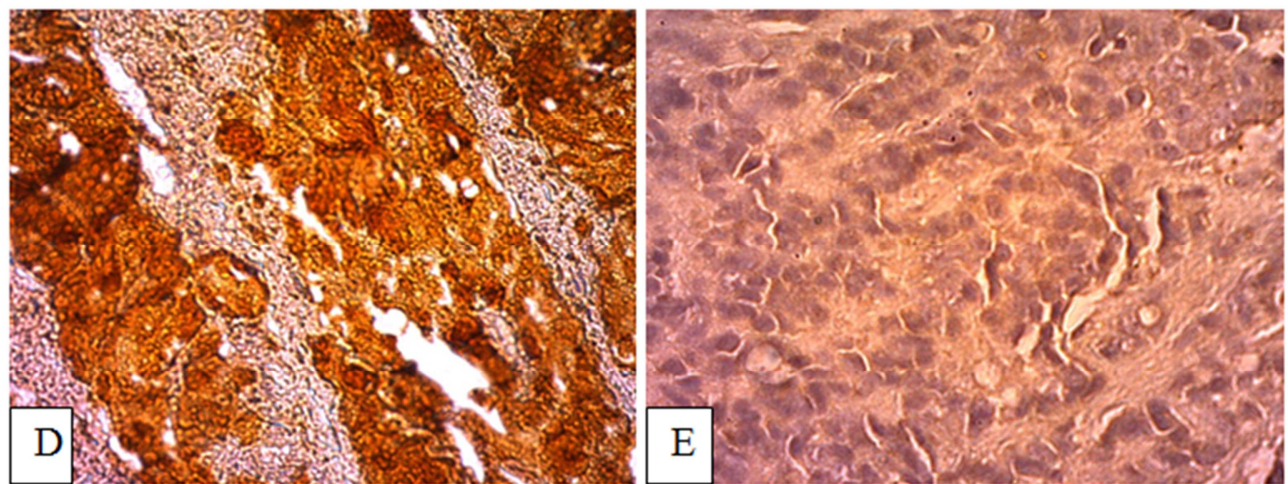

Figure 4. The lesional cells immunoreacted negatively for S100 protein. A: control; B test. 

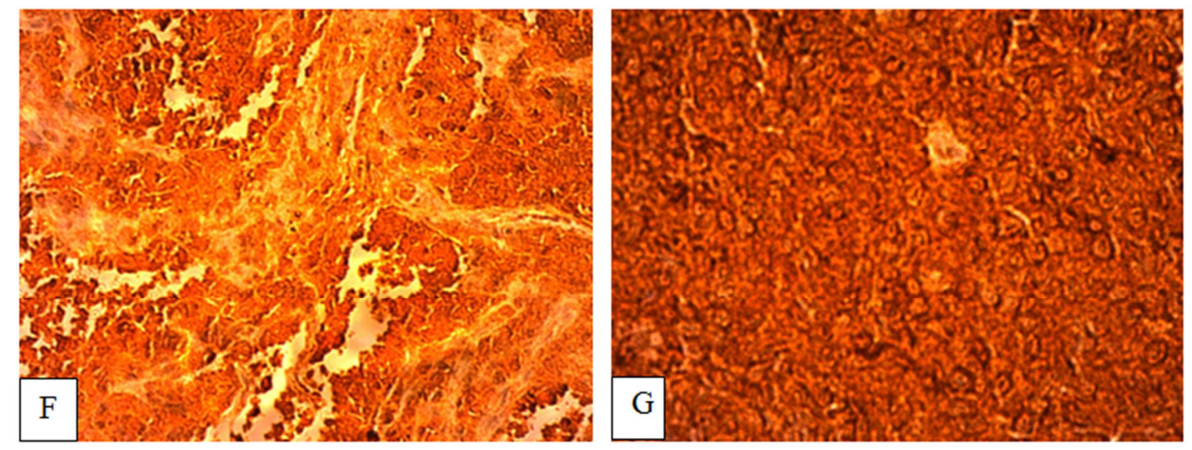

Figure 5. The lesional cells immunoreacted positively for cytokeratin and negatively for S100 protein. Appearances are consistent with a metastatic carcinoma. C: control; D: test.

Post-operatively, the patient was admitted to the intensive care unit for supportive therapy.

Serum Prostatic Specific Antigen (PSA) done subsequently was elevated with a value of $647,7 \mathrm{ng} / \mathrm{ml}(0-$ $4 \mathrm{ng} / \mathrm{ml})$.

On day 2 in ICU, the patient was still critically ill and in respiratory distress. He became pyrexial and the level of consciousness deteriorated to $5 / 15$.

On day 6 post-operation, the patient had deranged renal function with urea of $90 \mathrm{mmol} / \mathrm{L}$ and creatinine of $346 \mathrm{ml} / \mathrm{min}$ and a diagnosis of acute renal failure was made.

His general condition progressively deteriorated and he died 9 days after the operation.

\section{Discussion}

Subdural haematomas (SDH) are usually traumatic in aetiology. Non-traumatic instances of SDH are uncommon, and are rarely due to metastases involving the dura [3].

A heterogeneous subdural hematoma, consisting of blood products of different ages, has been considered highly suggestive of repetitive non-accidental head trauma. Recent literature has shown that heterogeneous signal intensity on

MRI can be a result of other causes, and not necessarily indicative of non-accidental trauma [4].

Carcinomatous infiltration of the dura from non-neurologic cancer is rare. It has been found at autopsy in 8 to $9 \%$ of cases of extraneural malignancy [3]

Laigle-Donadey et al found in a series of 198 cases of dural metastasis that the metastasis to the dura mater were cancers of the prostate $(19.5 \%)$, breast $(16.5 \%)$, lung (11\%), and stomach $(7.5 \%)$; therefore prostate cancer is evidently more susceptible to spread to the dura [5].

Metastasis to the dura and adjacent parenchyma occurs in 1 to 2 percent of patients with metastatic prostate cancer and is more common in those with tumors that do not respond to hormone-deprivation therapy [6].

Tremont-Luktas et al reported that in 118 cases of brain metastasis of prostate cancer, 19 spread to the dura. In a few cases, the diagnosis of dural metastasis was made following subdural bleeding. However, in other cases no blood was found during surgery, thus revealing the mimicking appearance of the subdural metastasis [7].

Recognition of this latter occurrence may help determine the best management for each individual case [3].

The time between the first diagnosis of prostate cancer and the discovery of the dural metastasis was highly variable ranging from 3 months to 7 years.

It has been suggested that the bleeding that precipitates the subdural hematoma could occur as a result of either: Rupture of fragile neo-vasculature within the metastatic deposits; Mechanical obstruction of dural veins and consequent dilation of upstream capillary beds, or hemorrhagic effusion from metastatic lesions due to an angiodesmoplastic reaction to the metastatic invasion [8].

A characteristic feature of malignant prostate carcinoma is its ability to promote tissue invasion (through MMP9), cancer cell survival (Caveolin-1 upregulation and promotion of cell survival through Akt-mediated activity and angiogenesis. Endothelial cell dysfunction in tumor microvasculature results in increased vascular permeability [9].

In unison, these features enable invasion of the dura, underlying membranes and promote leakiness that is compounded by coagulopathy. Disseminated intravascular coagulation (DIC) represents the result of a widespread activation of coagulation pathways and is the most frequent coagulation complication in prostate cancer [10]. In acute DIC there is a massive generation of thromboplastic material, as well as a consumption of haemostatic elements. Compensatory mechanisms are not sufficient to restore coagulation proteins and platelets. Consequently, transfusion of blood products is often indicated [11].

From 15 to 30 percent of metastases is the result of prostate cancer cells traveling through Batson's plexus to the lumbar spine. Haematogenous spread of Cancer cells to the dura from systemic malignant disease has also been suggested [12].

Metastatic disease in the lumbar area can cause spinal cord compression. Metastasis to the dura and adjacent parenchyma occurs in 1 to 2 percent of patients with metastatic prostate cancer and is more common in those with tumors that do not 
respond to hormone-deprivation therapy [13].

Patients rarely present with neurologic symptoms as the first manifestation of prostate cancer. Presentation with a solitary brain metastasis as the only site of prostate cancer spread is even rarer. Leptomeningeal metastasis (or carcinomatosis) is usually clinically silent, although it can present with deficits in multiple anatomic sites [14].

Gadolinium-enhanced MRI is required to exclude or confirm the presence of brain metastases. Compared with CT scanning, MRI is more sensitive in detecting multiple metastases, especially at the gray white junction [15].

Nevertheless, in patients with a contraindication for MRI, computed axial tomography (CAT) scan of the brain or PET(positron emission tomography) are the favoured options [16].

The serum prostate-specific antigen (PSA) level is highly predictive of bone metastasis. If the serum PSA level is above $100 \mathrm{ng}$ per $\mathrm{mL}$, the positive predictive value is 74 percent, if the serum PSA level is less than $10 \mathrm{ng}$ per $\mathrm{mL}$, the negative predictive value is 98 percent [17].

Unless seizures occur, the use of prophylactic anticonvulsants, particularly phenytoin (Dilantin), is not encouraged [18, 19]. In combination with radiotherapy, phenytoin may cause Stevens-Johnson syndrome (erythema multiforme major) [19].

Dexamethasone therapy should be started early, and referral to an oncologist is warranted. A two-week course of radiotherapy is the most common treatment for patients with multiple brain metastases or leptomeningeal involvement. Surgical removal of a solitary lesion usually extends survival [20].

Various stereotactic radiosurgical techniques, including the proton beam, gamma knife, linear accelerator (LINAC) gamma-knife and multileaf collimators with intensity modulators, are becoming more widely used for the condition. Because these modalities provide a precise beam of radiation, damage to surrounding normal tissue is limited [21].

Whole Brain Radiation Therapy In patients who have brain metastases that impinge upon eloquent areas or are too large, numerous, or disseminated for surgery or Radiosurgery or in patients that performance status does not allow for more aggressive therapy, WBRT alone remains the treatment of choice and provides effective symptom relief in the majority,

SRS is now standard practice for patients with 4 or fewer metastases in the brain and this has been validated by multiple prospective trials [22].

Although current level I evidence supports the use of SRS in patients with up to four brain metastases, specialists are already treating patients with many more than four brain metastases. Outcomes after Gamma Knife surgery (GKS) for multiple brain metastases have been defined in a number of retrospective studies over the past 2 decades. Routinely, patients harboring as many as 20 or more metastases are successfully treated in a single, minimally invasive, outpatient procedure. In most retrospective series, a higher number of metastatic lesions has not been shown to change survival for patients with more than five brain metastases if all are treated [23].

Brain metastasis is associated with a poor prognosis. Once prostate cancer has spread to the brain, the one-year survival rate is 18 percent, with an average survival of 7.6 months $[21,24]$.

\section{Conclusion}

It has been postulated that SDH development, in the presence of dural prostate metastasis, might be secondary to dural venous obstruction, hemorrhagic effusion (due to dural metastasis) or an angio desmoplastic response of the dura to the invasion by carcinomatous cells. In heterogeneous lesions that may appear as subdural collection, there is always need to exclude dural metastasis. It is always important to think of prostate metastasis in men.

In the stable patient with prostate cancer without gross or rapidly progressive neurological deficit, a contrast-enhanced MRI scan can be used to assess the extent of meningeal involvement and therefore the plausibility of complete resection along with evacuation of the collection.

\section{References}

[1] Kleinschmidt-DeMasters BK: Dural metastases. A retrospective surgical and autopsy series. Arch Pathol Lab Med 125: 880-887, 2001.

[2] McKenzie CR, Rengachary SS, McGregor DH, Dixon AY, Suskind DL: Subdural hematoma associated with metastatic neoplasms. Neurosurgery 27: 619-624; discussion 624-625, 1990 .

[3] Meyer P C, Reah T G. Secondary neoplasms of the central nervous system and meninges. Br J Cancer. 1953; 7(4): 438448.

[4] Soto-Ares G, Denes M, Noule N, Vinchon M, Pruvo JP, Gosset D. Subdural hematomas in children: role of cerebral and spinal MRI in the diagnosis of child abuse. J Radiol. 2003 Nov; 84(11 Pt 1): 1757-65.

[5] Laigle-Donadey F, Taillibert S, Mokhtari K, Hildebrand J, Delattre J Y. Dural metastases. J Neurooncol. 2005; 75(1): 57 61.

[6] Benjamin R, Neurologic complications of prostate cancer, Am Fam Physician. 2002 May 1; 65(9): 1834-40.

[7] Tremont-Lukats et al. Brain metastasis from prostate carcinoma: The M. D. Anderson Cancer Center Experience. Cancer 2003; 98: 363-368.

[8] Bobustuc G, Lagos G K, Lolas K, Kyritsis A P, Puduvalli V K. Brain metastasis from prostate carcinoma: The M. D. Anderson Cancer Center experience. Cancer. 2003; 98(2): 363-368.

[9] Hashizume H, Baluk P, Morikawa S, McLean JW, Thurston G, Roberge S, Jain RK, McDonald DM. Openings between defective endothelial cells explain tumor vessel leakiness. American Journal of Pathology 2000; 156: 1363-1380. 
[10] De la Fouchardiere C, Flechon A. Droz JP. Coagulopathy in prostate cancer. Netherlands. The Journal of Medicine. 2003; 61(11): 347-354.

[11] O'Meara C, Mahasneh T, Wilson P, I'Ons B, Alkhawaja D. Dural prostate metastasis resembling a chronic subdural haematoma. JSCR 2012 5: 7.

[12] Rumana CS, Hess HR, Shi WM, Sawaya R. Metastatic brain tumors with Dural extension. J Neurosurg 1998; 89; 552-558.

[13] Benjamin R, Neurologic complications of prostate cancer, Am Fam Physician. 2002 May 1; 65(9): 1834-40.

[14] Balm M, Hammack J. Leptomeningeal carcinomatosis. Presenting features and prognostic factors. Arch Neurol 1996; 53: 6 26-32.

[15] DeAngelis LM. Metastatic disease of the nervous system. Curr Treat Options Neurol 1999; 1: 409-16.

[16] J. L. Navarro-Olvera*, E. Arĩnez-Barahona, M. A. EsquedaLiquidano, A. Mũnoz-Cobos, Brain metastases: Literature review, Rev Med Hosp Gen Méx. 2017; 80(1): 60---66.

[17] Wolff JM, Bares R, Jung PK, Buell U, Jakse G. Prostatespecific antigen as a marker of bone metastasis in patients with prostate cancer. Urol Int 1996; 56: 169-73.

[18] Glantz MJ, Cole BF, Forsyth PA, Recht LD, Wen PY, Chamberlain $\mathrm{MC}$, et al. Practice parameter: anticonvulsant prophylaxis in patients with newly Diagnosed brain tumors. Report of the Quality Standards Subcommittee of the American Academy of Neurology. Neurology 2000; 54: 188693.

[19] Micali G, Linthicum K, Han N, West DP. Increased risk of erythema multiforme major with combination anticonvulsant and radiation therapies. Pharmacotherapy 1999; 19: 223-7.

[20] Gupta A, Baidas S, Cumberlin RK. Brain stem metastasis as the only site of spread in prostate carcinoma. A case report. Cancer 1994; 74: 2516-9.

[21] Patchell RA. The treatment of brain metastases. Cancer Invest 1996; 14: 169-77.

[22] Deepak Khuntia, Contemporary Review of the Management of Brain Metastasis with Radiation Hindawi Publishing Corporation Advances in Neuroscience Volume 2015, Article ID 372856, 13 pages.

[23] Ajay Niranjan, MD, MBA and L. Dade Lunsford, MD, Gamma Knife Radiosurgery for 5 to 10 Brain Metastases: A Good Option for Upfront Treatment, Oncology Journal, Brain Tumors, April 15, 2016, Oncology (Williston Park). 30(4): 314-315, 317.

[24] Fervenza FC, Wolanskyj AP, Eklund HE, Richardson RL. Brain metastasis: an unusual complication from prostatic adenocarcinoma. Mayo Clinic Proc 2000; 75: 79-82. 